http://jmscr.igmpublication.org/home/ ISSN (e)-2347-176x ISSN (p) 2455-0450 crossref DOI: https://dx.doi.org/10.18535/jmscr/v9i7.02

\title{
Original Research Article \\ Clinical and Investigation Profile of Patient of symptomatic Cholelithiasis Presenting in a Tertiary Level Institute at IGMC, Shimla
}

\author{
Authors \\ Dr Rakesh Gupta ${ }^{*}$, Dr Arun Chauhan ${ }^{2}$ \\ ${ }^{1}$ Senior Resident, Deptt. of General Surgery Indira Gandhi Medical College Shimla \\ ${ }^{2}$ Associate Professor, Deptt. of General Surgery, Indira Gandhi Medical College, Shimla, Himachal Pradesh \\ *Corresponding Author \\ Dr Rakesh Gupta \\ Senior Resident Deptt of General Surgery Indira Gandhi Medical College Shimla, India
}

\begin{abstract}
Cholelithiasis is one of the most common surgical conditions affecting gastrointestinal tract in North India and cholecystectomy is one of the most common surgery performed. Present study was performed to assess the clinical and investigational profile of symptomatic cholelithiasis patients at IGMC Shimla.

Aims and Objectives: This study was done to evaluate the Clinical and Investigation Profile of Patient of symptomatic Cholelithiasis Presenting In a Tertiary Level Institute.

Material and Methods: The study was conducted in 100 patients who underwent cholecystectomy for symptomatic gallstones in the Department of Surgery over a period of one year from July 2014 to June 2015. Patients were assessed for clinical presentations as well as investigational profile.

Results: Females were more commonly affected by gallstones with main presentations being pain abdomen, epigastric fullness, dyspepsia, nausea and vomiting. Ultrasound detected cholelithiasis in all patients and concurrent choledocholithiasis occur in 3\% patients for which MRI and MRCP was the best investigation to detect choledocholithiasis.

Conclusion: Cholelithiasis was most commonly seen in females in 4th and 5th decades and the main presenting complaints were pain in abdomen and dyspepsia, nausea and vomiting. Ultrasound is the preferred imaging modality for cholelithiasis with MRI and MRCP abdomen reserved for suspected choledocolithiaisis cases.
\end{abstract}

\section{Introduction}

Cholelithiasis is one of the most common surgical condition affecting gastrointestinal tract in North India and cholecystectomy is one of the most common surgery performed. ${ }^{(1)}$

Human bile is normally sterile. However in biliary tract obstruction bacteria may gain access to the biliary tract through papilla of vater or portal circulation. Systemic bacteremia may occur in severe cases. In 85 -95\% of cases inflammation of gall bladder is associated with calculi. ${ }^{(2)}$

Whether the stones represent a cause or effect has not been established. Persistent infection of biliary tract is one of the causes of gall stone formation. Incidence of gallstone disease is on a rise globally due to the vast changes in the dietary habits, life style changes associated with high junk diet consumption and increase sedentary lifestyle ${ }^{(3)}$. Its 
prevalence in India is estimated to be around 2 to 29\%, where it is most prevalent in Northern States as compare to Southern states. ${ }^{(4,5)}$

Changing scenario in India in mainly attributed to easy availability and access to investigation such as ultrasound in urban as well as rural areas and also because of increasing affordability. The present study aimed to evaluate Clinical and Investigation Profile of Patient of symptomatic cholelithiasis presenting in Himachal Pradesh (Northen India) in a tertiary level institute.

\section{Aims and Objectives}

The present study was done to evaluate clinical and Investigation profile of patients of symptomatic cholelithiasis presenting in tertiary level institute.

\section{Material and Methods}

The present study was done at department of General Surgery at IGMC, Shimla a tertiary care hospital. It was an observational study carried out in an academic hospital over a period of 1 year from July 2014 to June 2015. The study was conducted on 100 patients above 18 years age with ultrasound proven symptomatic gallstone disease patients were included in the study. Demographic factors such as age and gender were studied. Clinical factors based on the history, pain abdoman, dyspepsia, nausea, vomiting were assessed. Baseline blood investigations of the patient were done (complete haemogram, fasting blood sugar, liver function test) in all patients. Fasting USG abdomen was done on all study patients with MRI abdomen with MRCP (Magnetic Resonance Cholangio Pancreatography) performed on reserved for patients with cholelithiasis with dilated CBD more than $7 \mathrm{~mm}$; raised alkaline phosphatase or with suspicion of choledocholelithiasis. All patient underwent Surgery by faculty of Department of Surgery, IGMC Shimla. Open cholecystectomy, Laparoscopic cholecystectomy, CBD exploration and cholecystostomy were the operations that were performed.

\section{Results}

A total of 100 patients of gallstones were enrolled with a mean age of 46.27 years with age ranging from 18 to 75 years. We divided patients into 3 groups $\leq 30,>30-50$ and more than 50 years. The no. of patients in age group $>30-50$ were much significantly more than that of the other groups. In this study female patients were 82 and male patients were 18 and the ratio between female and male was 4.55: 1.

Patients presented with Pain right upper abdomen in $100 \%$, sense of epigastric fullness on $10 \%$, flatulence dyspepsia in $8 \%$, intermittent nausea and vomiting in $15 \%$ as shown in Table no 1.12 of the patients in the present study were having co morbidities like hypertension, diabetes, bronchial asthma, tuberculosis and ischemic heart disease shown in Table 2

Table No 1: Clinical Features of Patients

\begin{tabular}{|l|c|c|}
\hline Clinical Presentation & No & Percentage (\%) \\
\hline Pain right upper abdomen & 100 & $100 \%$ \\
\hline Sense of epigastric fullness & 10 & $10 \%$ \\
\hline Flatulence Dyspepsia & 8 & $08 \%$ \\
\hline Nausea and vomiting & 15 & $15 \%$ \\
\hline
\end{tabular}

Table no 2: Associate Disease (Co morbidity)

\begin{tabular}{|l|c|}
\hline Diseases & Number \\
\hline Hypertension & 4 \\
\hline Diabetes mellitus & 4 \\
\hline Bronchial asthma & 2 \\
\hline Pulmonary tuberculosis & 1 \\
\hline Ischemic heart disease & 1 \\
\hline Total & 12 \\
\hline
\end{tabular}


Table No 3: Routine Investigations (Biochemical / Blood Investigations)

\begin{tabular}{|l|c|c|c|}
\hline Investigations & Range & Mean & SD \\
\hline Haemoglobin & 10 to $14 \mathrm{gm} \%$ & $11.63 \mathrm{gm} \%$ & 1.315448 \\
\hline Total leukocyte count & 7000 to $11000 \mathrm{~mm}^{3}$ & $9499 \mathrm{~mm}^{3}$ & 1066.80 \\
\hline ESR & 10 to $20 \mathrm{~mm} \mathrm{in} 1^{\text {st }} \mathrm{hr}$ & 15.8 & 2.23 \\
\hline Blood urea & 15 to $45 \mathrm{mg} \%$ & 38.6 & 4.5 \\
\hline Blood sugar & 70 to $140 \mathrm{mg} \%$ & 109 & 20.4 \\
\hline Serum bilirubin & 0.2 to $0.8 \mathrm{mg} \%$ & 0.68 & 0.14 \\
\hline SGOT & 5 to $43 \mathrm{Units}$ & 34.6 & 4.5 \\
\hline SGPT & 5 to 37 Units & 29.6 & 4.5 \\
\hline Alkaline phosphate & 25 to 90 Units & 60.9 & 10.9 \\
\hline
\end{tabular}

Hemoglobin, total leukocyte count, erythrocyte sedimentation rate, blood urea, blood sugar and liver function tests which included serum bilirubin, alkaline phosphate, SGOT and SGPT were done in all the patients. The investigations were within normal limits except few patients. .In four patients total leukocyte count was more than $12000 / \mathrm{mm}^{\wedge} 3$. In four patients suffering from diabetes mellitus blood sugar, fasting and postprandial was between 160 to $240 \mathrm{mg}$. The diabetes mellitus was controlled by Injection Insulin and patients were subsequently operated. Two of the patients had raised alkaline phosphatase; the value being 150 units and 160 units respectively but no choledocholithiasis.

Abdominal ultrasound was the investigation of the choice for diagnosing cholelithiasis. Out of 100 patient single calculus was seen in $20 \%$ and multiple calculi in $80 \%$ of the patients. $90 \%$ had distended gall bladder and in $10 \%$ there was contracted gall Bladder. Out of $90 \%$ of distended gall bladder 2 were of empyema gall bladder while 8 had mucocele. In 5 patients gallstones were associated with acute cholecystitis. 5 had Wall Echo sign (W.E.S) on imaging. In 15 patients gallstones were associated with dilated CBD with stones while 8 patients had dilated CBD without stones as shown in Table no. 4.

All the 100 patient underwent surgery in which $74 \%$ underwent open surgery and $26 \%$ underwent laparoscopic surgery.

Table No 4: Ultrasound Findings

\begin{tabular}{|l|l|}
\hline A. Size of Gall Bladder & $80 \%$ \\
\hline Gall Bladder distended (normal) & $08 \%$ \\
\hline Mucocele & $02 \%$ \\
\hline Empyema & $10 \%$ \\
\hline Gall Bladder contracted & $80 \%$ \\
\hline B. Calculi & $20 \%$ \\
\hline Multiple Calculi \\
\hline Single Calculus \\
\hline C. CBD & $15 \%$ \\
\hline CBD dilated (with stones) & $08 \%$ \\
\hline CBD dilated (without stones) \\
\hline D. Acute Cholecytstitis & $05 \%$ \\
\hline Features suggestive of Acute Cholecystitis \\
\hline E.WES \\
\hline Wall Echo Sign \\
\hline
\end{tabular}

Table 5: Operative management in patient of cholelithiasis.

\begin{tabular}{|c|c|c|c|}
\hline & Type & No of Patients & Percentage \\
\hline A & Open surgery & 74 & $74 \%$ \\
\hline 1 & Open cholecystectomy & 56 & $56 \%$ \\
\hline 2 & Open cholecystectomy with choledocholithotomy & 12 & $12 \%$ \\
\hline 3 & $\begin{array}{l}\text { Open cholecystectomy with choledocholithotomy with } \\
\text { choledochoduodenostomy }\end{array}$ & 6 & $6 \%$ \\
\hline $\mathrm{B}$ & Laproscopic Surgery & 26 & $26 \%$ \\
\hline 1 & Laproscopic Cholecystectomy & 26 & $26 \%$ \\
\hline & Total & 100 & $100 \%$ \\
\hline
\end{tabular}




\section{Discussion}

Cholelithiasis is most commonly prevalent in northern states of India as compared to southern states. It is 7 time higher in Northern State. There are very few studies performed for prevalence in central India. The mean age in present study was 46.27 years. Maximum patients presented in $4^{\text {th }}$ and $5^{\text {th }}$ decade in the present study which is suggestive of early occurrence of gallstones disease in Indian population that is consistent with other studies conducted in other states which report occurrence of these cases in $4^{\text {th }}$ and $6^{\text {th }}$ decade of India. The decade of peak incidence in present study is same for both gender. In our study most of the cases undergoing surgery were in the age group of 31-60 years and incidence of cholelithiasis was highest in $5^{\text {th }}$ decade. This difference indicate geographical variations with incidence of cholelithiasis.

Pain in abdomen was the most common presentation of cholelithiasis. In the present study all patient had pain. This finding is well documented in the literature $(10)(11)(12)(13)$. Dyspepsia was seen in $5 \%$.While nausea and vomiting was seen in $10 \%$.

Ultrasonography is the procedure of choice in suspected gall bladder or biliary disease. It is a sensitive, specific, non invasive and in expensive test for the detection of gall stones(10). Moreover it is simple, rapid and safe in pregnancy and it does not expose the patient to harmful radiation or I.V. contrast. Added advantage is the it can be performed by skilled practitioner at the bed side. Sensitivity is vulnerable and depending upon the operater's proficiency, but in general, it is highly sensitive and specific for gallstones greater than $2 \mathrm{~mm}$. It is less so for microlithiasis or biliary sludge. Ultrasound findings of gallstones (Cholelithiasis). Ultrasound is very useful for diagnosing uncomplicated acute cholecystitis. The sonography feature of acute cholecystitis includes gall bladder wall thickening (> $5 \mathrm{~mm}$ ), pericholecystic fluid, gall bladder distention (> $5 \mathrm{~cm}$ ) and sonographic Murphy's sign. The presence of multiple criteria increased its diagnostic accuracy. Gall stones appear as echogenic foci in the gall bladder. They move freely with positional change and cast an acoustic shadow. Magnetic resonance imaging (MRI) with Magnetic Resonance Cholangiopancreatography (MRCP) has emerged as an excellent imaging study for the noninvasive identification of gallstones anywhere in the biliary tract, including the common bile duct. Because of its cost and the need for sophisticated equipment and software, it is usually reserved for cases in which choledocholithiasis is suspected. The 2010 ACR guidelines recommend MRI as a secondary imaging study in ultrasound acute cholecystitis or gallstones. In the present study ultrasound failed to pick CBD stones in $08 \%$ patients which were picked up by MRI showing its efficiency in detection of biliary tract pathology / CBD stone observed on ultrasonography. The incidence of choledocholithiasis increases with presence of multiple gall bladder stones and is better detected by MRI abdomen and MRCP. TLC might be a good indicator of difficult Gall Bladder. All patients $(100 \%)$ in the study underwent surgery. The percentage of patients undergoing laparoscopic were $26 \%$, open cholecystectomy were $74 \%$. Post ocomplications in laproscopic group and open cholecystectomy group were compared in the present study, it was observed that the complications like bile leak, surgical site, infection and fever were found more after the open cholesystectomy as compared to laproscopic (14)(15). Most common histopathological finding was chronic cholecystitis, followed by acute cholecystitis. Following the advent of laparoscopic surgery, with its accompanying smaller in incisions, less pain and shorter hospitalization, surgeons have performed an increasing number of laparoscopic cholecystectomies. Acute cholecystitis carries longer operative times and a higher conversion rate to the open procedure than when laparoscopic cholecystectomy is performed in elective setting. Absolute contraindication of laparoscopic cholecystectomy inability to tolerate GA carcinoma Gall bladder and peritonitis and coagulopathy. Relative contraindications are end-stage liver disease with portal hypertension chronic obstructive 
pulmonary disease. Complications of laparoscopic cholecystectomy occur in $<2 \%$ of all the cases. Trocar/Veres needle injury(0.2\%), Haemorrhage, Wound infection/abscess, Paralytic Ileus, Bile Leak, Gall Stone spillage, Deep vein thrombosis, Retained common bile duct stone, CBD injury $(0.1 \%-0.5 \%)$, Pancreatitis Conversion to open procedure $(<5 \%)$. The two most frequent indications for conversions are dense upper abdominal adhesion and in necrotic gall bladder wall. Lack of adequate exposure. CBD injuries are less in open cholecystectomy $(0.2 \%)$.

\section{Conclusion}

Cholelithiasis is commonly seen in female in $4^{\text {th }}$ and $5^{\text {th }}$ decade mainly presenting with pain abdomen, dyspepsia ,nausea and vomiting. Ultrasound is the main diagnostic modality to detect gallstone with MRI and MRCP reserved for patients suspected to have choledocholithiasis. Laparoscopics cholesystectomy offers the best possible surgery for gall bladder stone disease patients with minimal morbidity.

\section{Source of Support: None}

Funding: No funding sources.

Ethical approval: The study was approved by institutional ethics committee.

\section{Reference}

1. Tandon RK. Prevalence and type of biliary stones in India. World J Gastroentero, 2000;6 (Suppl 3):4-5

2. PRL Gomes1 et al. Aerobic bacteria associated with symptomatic gallstone disease and their antimicrobial susceptibility. Faculty of Medical Sciences, University of Sri Jayawardenapura, Nugegoda. Vol 11: No 1, September 2006

3. Haribhakti SP Mistry JH Techniques of laparoscopic cholecystectomy: Nomenclature and selection. J Minim Access Surg. 2015;11(2):113 8.

4. Unisa S. Jagannath P. Dhir V. Khandelwal C Sarungi L, Roy TK, Population-based study to estimate prevalence and determine risk factors of gallbladder diseases in the rural Gangetic basin of North India. Hpb. 2011;13(2):117-25.

5. Tendon R. Diseases of gallbladder and biliary tract APL Textbook of Medicine. 7th ed. Shah DSN. editor. 2003:642-4

6. Chhutani PN. Sachdeva Y, Chitkara NL, Thind RS, Chawla LS. Gall Bladder Disease in Punjab: Incidence and Symptomatology. J Assoc Phys. India. 1965:13:140-5

7. Sabharwal ED. Chopra R, Chawla LS.Gall bladder disease pattern in Punjab. J Indian Med Assoc. 1984;82(5):164-6.

8. Manan F, Khan M, Faraz A, Khan M. Frequency of common bacteria and their antibiotic sensitivity in patients with symptomatic cholelithiasis. Journal of Postgraduate Medical Institute. 2014;28:2

9. Cirillo DJ. Wallace RB, Rodabough RJ. Greenland P, La Croix AZ, Limacher MC, et al. Effect of Estrogen Therapy on Gallbladder Disease. JAMA 2005:293 (3):330.

10. Kumar Verma S. Das R, Gaurav K. Epidemiology and in management of gall stone disease in tribal population of eastern India. IJIRR.2016,3(12);3361-3

11. Lokesh K Siddavaram S. A Clinical study of gall stone disease. Orig Res Artic J Evid Based Med healTu20 17:4(194):5789-.97

12. Jai Kumar Misrani. Sadaf Iqbal, Nazir Ahmed SarolizA M. Ahmedani SA. Comparative Study of clinical Profile in Patients with Solitary versus Multiple gall Stone. J Liaquat Uni Med Health Sci 2016;15(1): 12-5

13. Rao KS Ravi K. A Prospective Study on Cholelithiasis s and Its Complications. IOSR J Dent Med Sci 2017:16:1-04

14. Rachamalla RR. Markapuram KK, Satish S. A one year study of Cholelithiasis at a tertiary care hospital of south india. Int Surg J . 1. 2018;5(7):2444

15. Muthalaisamy DP, Rajachidambaram DK, Karthick DP. Clinicopathological evaluation 
JMSCR VoI||09||Issue||07||Page 05-10||July

of cholelithiasis and management strategies at a tertiary care hospital. Glob J Res Anal. 2018;6(12): 90-4

16. Fischer's Mastery of surgery $6^{\text {th }}$ Edition Volume 1 Page no 1271, 1272. 